\title{
REVIEW
}

\section{Open Data requirements for applied ecology and conservation: case study of a wide-ranging marine vertebrate}

\author{
Gail Schofield* \\ Deakin University, Geelong, Australia. School of Life and Environmental Sciences, Centre for Integrative Ecology, \\ Warrnambool, VIC 3280, Australia
}

\begin{abstract}
Wide-ranging animals often traverse more than one country, making it important to establish international management co-operations and agreed protocols; however, accessing all available information on a given species, or even a population of interest, compiled by local, national and international organisations, is often complicated. In the case of sea turtles, this issue is further compounded because different life stages of the same population occupy different types of habitat; even as adults, while part of the population aggregates to breed at a single site in a given year, all other adult individuals are dispersed across foraging habitats up to $1000 \mathrm{~km}$ or more in distance. Information on the number of individuals, movement patterns and habitat use are needed to: (1) identify, select and conserve key breeding, foraging and developmental habitat effectively, (2) develop realistic models to predict current and future threat status of animals as accurately as possible, and (3) mitigate pressures operating in distant areas that, otherwise, might not be detected or linked to the population of interest. Here, I use sea turtles as a case study to show how our current knowledge on wide-ranging marine species is currently incomplete and, in many cases, disjointed. In particular, different techniques are often used to assimilate different types of information in different settings for different purposes (e.g. mark-recapture, genetics, strandings and nesting data). Ultimately, opening access to these data sources would facilitate major advances in research, as well as the transfer of knowledge and information to practitioners, allowing the effective implementation of conservation management.
\end{abstract}

KEY WORDS: Open Access - Open Data - Data integration - Modelling - Species extinction · Wildlife $\cdot$ Natural resource management

\section{INTRODUCTION}

Access to data gives users the ability to discover, retrieve and manipulate data, extracting useful information for the implementation and monitoring of biodiversity to protect wildlife (Turner et al. 2015). Long-term field data collected on wildlife species, particularly those threatened with extinction, are essential for implementing appropriate conservation, by providing irreplaceable information on move-

${ }^{*}$ Corresponding author: g.schof@gmail.com ment, habitat use and population demographics (Costello \& Wieczorek 2014). However, often, only limited (potentially biased) datasets are available to managers or policy makers, or even to experts from different disciplines attempting to integrate diverse datasets, preventing optimal use and robust interpretation (Reichman et al. 2011). Consequently, there have been increasing calls for 'data sharing' (e.g. Open Access or Open Data), with the establishment of online depositories and archiving policies facilitat-

() The author 2017. Open Access under Creative Commons by Attribution Licence. Use, distribution and reproduction are unrestricted. Authors and original publication must be credited. 
ing the free access and permanent availability of data from all fields of ecology (Reichman et al. 2011, Turner et al. 2015). Open Access is particularly important for research on wildlife species with ranges that span multiple countries and climatic zones, with data sharing potentially providing a way to fill existing knowledge gaps and improve global-level conservation efforts. Here, I use sea turtles as an example to highlight how Open Access could help connect information collected by independent groups to fill gaps on population habitat use and dynamics, as well as provide a means for experts from different disciplines to integrate these data with other parameters (environmental, climate, threats, etc.) to improve conservation efforts. In particular, a multidisciplinary approach is required to understand how the physiology, behaviour and population status of individuals from different areas within a given species home range drive life-history processes.

Long-distance migratory animals present many challenges to conservation (Shaffer et al. 2006, Shillinger et al. 2008). Migratory animals rarely remain within one country; thus, conservation actions in one country might be countered by detrimental actions in another country (Wilson et al. 2004, Carroll \& Miquelle 2006). However, without general access to information being collected by involved groups, information gaps arise, leading to inaccurate assumptions on recovery or threats (Shillinger et al. 2008, Womble \& Gende 2013). It is difficult to manage (i.e. monitor and regulate) potentially detrimental human activities across the vast areas used by migratory animals, especially when different countries might have different regulations or concessions (e.g. Hyrenbach et al. 2000, Hooker et al. 2011). At the governmental level, the minimal investment (or fewest hurdles to overcome) for the maximal output is logically sought (Shogren et al. 1999). Therefore, it is in the best interests of local, national and international researchers and conservation organisations to make their data accessible, which would inform practitioners about broad-scale distribution and habitat requirements of target species to establish the long-term viability of populations, and predict the consequences of environmental processes and/or human disturbance on these populations and for effective conservation planning (Wilson et al. 2004, Carroll \& Miquelle 2006).

Consequently, the question of how to conserve such broad-ranging species effectively is raised, particularly as researchers in a given country may only have information on one component of the life history of a given species. For instance, sea turtles are the only reptiles that are known to migrate long dis- tances between breeding and foraging sites (see Godley et al. 2010, Southwood \& Avens 2010). While sea turtles are found in all ocean basins, the Mediterranean Sea presents a strong example of the complexity of protecting this group of long-distance dispersers and migrators, with over 21 nations on 3 continents bordering this basin. Sea turtles range over almost every part of the Mediterranean (for an overview, see Luschi \& Casale 2014) to access important resources, such as optimal beaches for nesting and optimal oceanic and coastal marine habitats for foraging and development (Bjorndal 1997, Hatase et al. 2002, Bolten 2003, Hawkes et al. 2006, Casale et al. 2012, Schofield et al. 2013). Consequently, we have different life-history stages dispersed throughout the Mediterranean, but with non-uniform distributions (Clusa et al. 2014). As a result, it is difficult to mitigate existing and future natural and anthropogenic threats (Coll et al. 2010, Wallace et al. 2010, 2011, Mazaris et al. 2014). Thus, open access data and multi-disciplinary collaborations are needed to protect such species with complex life histories.

Such threats include an increase in the exploitation of resources (including fisheries), use and degradation of habitats (including coastal development and agriculture), pollution and climate change (Mazaris et al. 2009a,b, 2014, Casale \& Margaritoulis 2010, Katselidis et al. 2012, 2014). Casale (2011) estimated that there are more than 132000 incidental captures per year in the Mediterranean, of which more than 44000 are predicted to be fatal. Higher than expected mortality might reduce the resilience of this group of species, negatively impacting the ability of populations to recover (Coll et al. 2010, Wallace et al. 2010, 2011). Furthermore, the risk of extinction is particularly high in the Mediterranean because the breeding populations of both loggerhead and green turtles are demographically distinct from other global populations (Encalada et al. 1998, Laurent et al. 1998), and might not be replenished. In addition, evolutionary processes and adaptive regimes drive differentiation in the behaviour and biology of populations of the same species (e.g. Mazaris et al. 2015). Therefore, it is important to obtain detailed knowledge about the numbers of sea turtles that frequent different foraging habitats, along with the distribution and connectivity between these sites (Hamann et al. 2010, Mazaris et al. 2017).

Through reviewing the inherent complexity of the main life-history stages and biological components of sea turtles, I highlight the need for data sharing as the only means to improve our understanding of this group of species, and conserve them effectively (see 
Fig. 1 for overview). This review first considers demographic information and the lack of information on actual numbers of adults and juveniles in populations. As most research focuses on estimating adult females from nest counts at breeding areas, I further point out the need to link data collected at breeding sites and foraging sites, filling information gaps on recruitment and potential changes in reproductive output linked to climate change, from which realistic population models could be developed. Such approaches require researchers across different regions to collaborate to piece together information on the

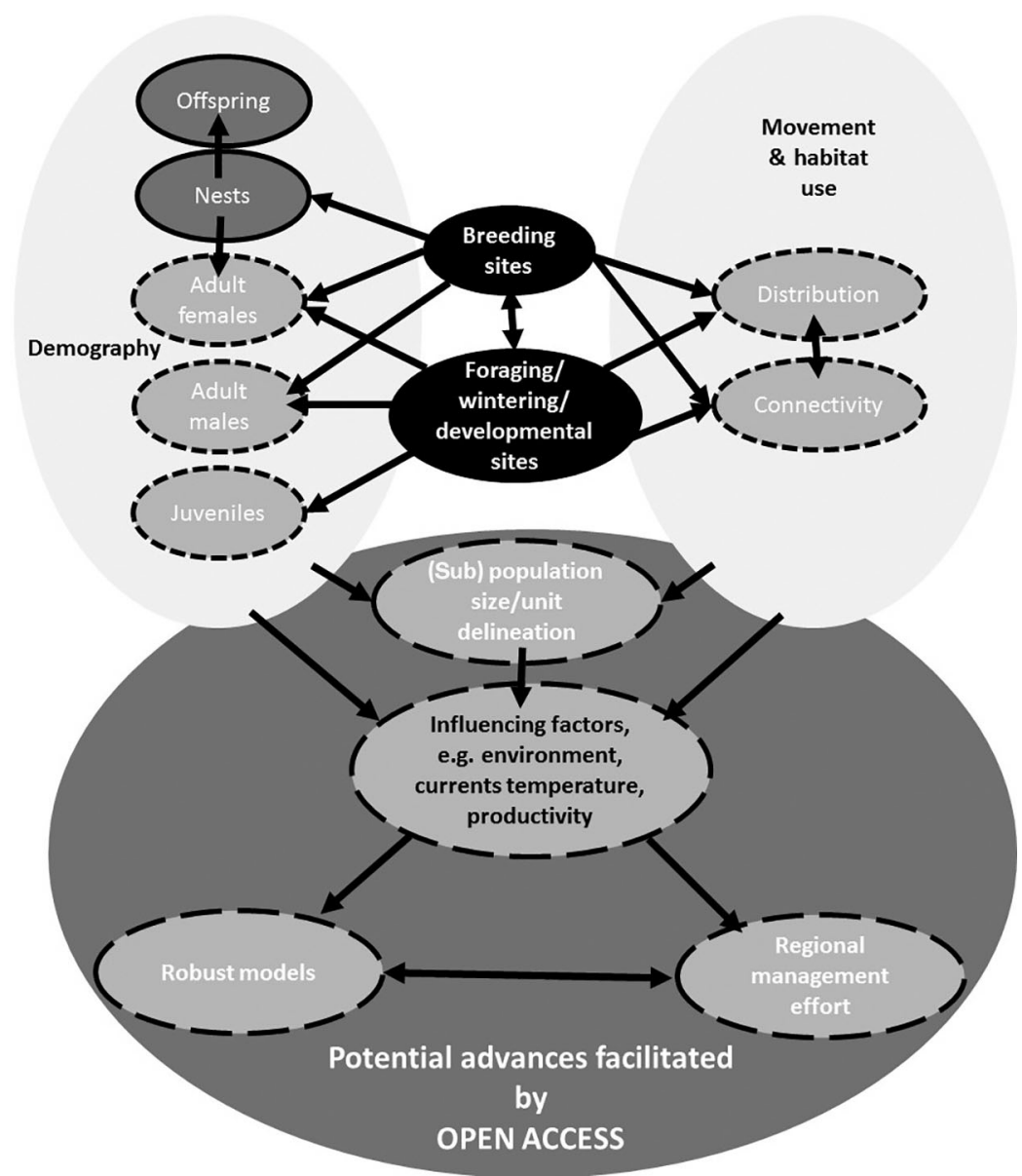

Fig. 1. Schematic showing how Open Data represents an important tool to advance the monitoring and conservation of wildlife by consolidating datasets of species with highly dispersed habitat use and life stages: a case study of sea turtles. Within the Mediterranean, most knowledge exists on nesting site distribution and nest (including offspring) numbers; however, knowledge on the connectivity among nest sites (males and females) and foraging (wintering and developmental) grounds, along with the demography (source breeding populations) and numbers are required to determine actual population units and influencing factors to construct robust models and implement effective management. Continuous outlines and dark grey shading $=$ strong regional knowledge; short dashed outlines and intermediate grey shading $=$ local scale or intermittent knowledge only; long dashed outlines and intermediate grey shading $=$ general lack of consistent regional-scale interpretation at present same population, as well as multidisciplinary collaborations to assess potential trends.

\section{NUMBERS}

\section{Adult females}

Open Access could provide a way to regularly update information on sites with different nesting patterns, from which broader ecological significance could be determined. For instance, the nesting sites of loggerhead and green turtles in the Mediterranean are concentrated in Greece, Turkey and Cyprus; however, many nesting sites in these and other countries are not regularly monitored, or the data are not published, due to low or sporadic nesting effort, making it difficult to publish this information. Yet, this information could provide insights into the pressures potentially driving sea turtles to seek out alternative sites (Almpanidou et al. 2016), such as climate change and associated sea level rise.

Open Access could be used to integrate environmental information in models of population abundance estimated from field surveys with incomplete detection. Furthermore, Open Access could help link reproductive behaviour to foraging parameters to build models that are able to incorporate all of these factors. Sea turtles are ectotherms, with environmental conditions such as sea temperature and forage resource availability influencing the seasonality and timing of reproduction (Broderick et al. 2001, 2003, Hays et al. 2002, Schofield et al. 2009, Hamann et al. 2010, Fuentes et al. 2011). Consequently, there is great variability in different reproductive parameters, including the number of eggs per clutch, breeding periodicity and survival related to foraging habitat use (Hays et al. 2014). For instance, high environmental variability likely leads to overestimates of female population size in warmer years and underestimates in cooler years (Hays et al. 2002). As a result, concerns have been 
raised about the reliability of using nest counts of females alone to infer sea turtle population trends (Mazaris et al. 2008, 2017, Pfaller et al. 2013, Whiting et al. 2013, 2014). Estimates of sea turtle abundance are typically obtained from foot patrols on nesting beaches counting the number of females (usually during the peak 2-3 wk of nesting) and/or their nests (Limpus 2005, Pfaller et al. 2013, Whiting et al. 2013, 2014, Hays et al. 2014). However, some females might not be detected by foot patrols because they nest at a different time of the season (particularly at tropical sites with extended seasons) when monitoring effort is not in effect or they nest on beaches that are not patrolled at all. Consequently, it is broadly assumed that females lay 3 clutches on average, even though 5 or more clutches might occur at some sites (Zbinden et al. 2007, Katselidis et al. 2013). Thus, current estimates of 2280-2787 and 339-360 adult female loggerhead and green turtles, respectively, nest each year in the Mediterranean (Broderick et al. 2002, Casale \& Margaritoulis 2010) might be major underestimates.

Because sea turtles have long life spans, it is extremely important to use permanent forms of identification (e.g. passive integrate transponder [PIT] tagging, DNA fingerprinting, photo-identification) of all life stages that are documented in Open Access databases, allowing records of live and dead individuals to be compiled throughout the region. Such information would provide novel information on the survival rates of different life-history stages, facilitating the development of robust models on population trends, which are currently not possible. For instance, factors impacting turtle population dynamics in the coming decades will not be detected from nest counts for another 30 to $50 \mathrm{yr}$ (Scott et al. 2012), because this is the generation time of this group and nest counts cannot predict how many juveniles are recruiting into the populations until they begin nesting themselves. This time frame will likely be far too late to save many populations. Ultimately, trends in abundance at nesting sites are synthesised in species assessments through the International Union of Conservation for Nature (IUCN), which broadly categorises the conservation status of species (IUCN 2016). Therefore, a combination of tagging methods should be used to quantify female numbers as accurately as possible (e.g. Dutton et al. 2005, Stokes et al. 2014, Mazaris et al. 2017). Such tagging methods could include photo-identification and PIT tagging, allowing information on recruitment into the breeding population and longevity of nesting by individuals to be documented (e.g. leatherbacks nesting at St Croix; Dutton et al. 2005).
Open Data and fast communication are essential to 'track' changes to nesting activity in relation to the broader environment (e.g. nesting habitats) used by turtles. To achieve this, Open Data on various monitoring databases is needed, in parallel to environmental conditions at foraging areas, to capture how variation in nest numbers and animals reflects conditions at distant foraging habitats (Broderick et al. 2001, Mazaris et al. 2009a,b). For instance, the spatial extent of the nesting beaches, the great variability in reproductive parameters and the long life span of sea turtles clearly show how population properties can only be obtained by assimilating nesting site information to a population level (e.g. termed regional management units for sea turtles; see Wallace et al. 2010, 2011). By failing to accumulate long time series from all monitored nesting sites, it is not possible to provide accurate assessments of true population dynamics, limiting the development of population models that must rely on, potentially inaccurate, assumptions (e.g. Broderick et al. 2002, Mazaris et al. 2005). For instance, declines in nest numbers at one site paralleled by an increase in numbers at an adjacent site might not reflect any change at the population level, but could be used to investigate the causes (natural versus anthropogenic) in these changes of site use. Furthermore, such information could inform us on distributional shifts and changes to phenology linked to climate change (Almpanidou et al. 2016), which would help with the detection and advanced protection of future viable nesting and foraging sites.

\section{Adult males}

Open Access could help consolidate important information about elusive components of wildlife populations across multiple sites for fast integration into management and population studies. For instance, while much effort has been placed on monitoring nesting activity, nest counts cannot inform us about the number of adult males, the number of juveniles being recruited into the adult population, the longevity of nesting by individuals or mortality rates. Yet, these parameters inform us of the viability and health (e.g. genetic diversity) of populations (Limpus 1993, Schofield et al. 2009). It is necessary to estimate the number of males in a breeding population, but it is difficult to make such counts because males remain in the sea, i.e. they do not emerge on beaches like females. 
Open Access could help inform managers about the timing of breeding and habitat use by different components of populations (e.g. males versus females) across multiple sites. Such information would allow protective legislation to be updated, such as the timing and delineation of protective zoning, over a broad region (i.e. at multiple sites, based on data obtained from focal sites) to protect the components of populations that might be at greater risk. For instance, offspring sex ratios are highly female biased; however females breed up to every $3 \mathrm{yr}$, while most males breed annually (although some of those that forage off Tunisia/Libya and in western Greece return biannually; Limpus 1993, Hays et al. 2014, Casale et al. 2013). Thus, while only small numbers of males might be needed to mate large numbers of females (as evidenced by high levels of multiple paternity; Zbinden et al. 2011), too few males might lead reduced genetic diversity and potential bottlenecks. Thus, if we assume 2280-2787 adult female loggerheads in the Mediterranean (Broderick et al. 2002), there may be just 580 to 696 adult loggerhead males in total, based on offspring sex ratio skews (Hays et al. 2014). The presence of any male-biased mortality could, therefore, threaten the persistence of sea turtle populations in the Mediterranean. Thus, it is essential to determine how many males breed at each nesting site, and if the same males breed at more than one site, as well as which foraging sites they frequent, and any potential mortality risks they are exposed to. Such information could only be assimilated by the parallel investigation of breeding and foraging sites across different countries, along with information on various threats, including fisheries and pollution. This information will help practitioners to understand the need to focus effort on protecting habitats frequented by males, as well as informing researchers on operational sex ratios and adult sex ratios at the population level.

\section{Immature stages}

Because bycatch via fisheries is predicted to be a major threat to the survival of juvenile sea turtles inhabiting oceanic and coastal environments (Casale et al. 2014), it is essential to share information on the distribution of juvenile turtles and the types of fisheries and the threat posed (Costello \& Wieczorek 2014), along with information on other pressures operating at different scales. Open Data would provide a way to overlay all of these different components to identify actual hotspots, rather than hotspots generated through sampling bias. Open Data could provide a fundamental way of assimilating data gathered by different techniques to monitor wildlife in the marine environment (aerial surveys, incidental capture in fishing gear and direct capture; e.g. Cardona et al. 2005, Casale 2011, Casale et al. 2012, Rees et al. 2013). This approach would generate a representative cross-section of juveniles that are sampled across the entire Mediterranean ocean basin for integration in various demographic and climate change models. Sharing such data would also provide an incentive to standardise methods, which, in turn, would improve the robustness of models, along with lags in interpreting trends in relation to certain threats. Models based on egg counts, the emergence success of offspring and fisheries bycatch indicate that immature turtles represent the greatest component of the population (Hirth \& Schaffer 1974); thus, information on the size structure and abundance at foraging grounds is essential to understand changes in nest counts, based on changes in mortality and recruitment into adult breeding populations (Demography Working Group 2015). However, because the juveniles of each nesting population are dispersed across multiple habitats in multiple countries, obtaining counts of individuals from a single nesting site or population is difficult, requiring cross-country collaboration, along with the complementary use of genetic sampling (Casale \& Margaritoulis 2010). Ultimately, monitoring changes to survival probability across time would help inform assessments of conservation status for different immature life stages, as well as indicate the magnitude of local threats.

\section{DISTRIBUTION AND CONNECTIVITY}

\section{Nesting sites}

Open Data could offer a way to overcome bias on key components of nesting sites, due to the lack of information on low or sporadically nested sites. For instance, Open Access could provide research groups regional-scale information on the distribution and characteristics of nesting sites (Katselidis et al. 2013), facilitating the development of robust predictions on future habitat shifts in relation to climate change, as well as ensuring that protected areas remain viable in the future (Fuentes et al. 2011, Mazaris et al. 2014, Almpanidou et al. 2016). Open Access could also help fill in gaps on how many nesting sites constitute a single 'population unit', with the gene flow of males being assumed to represent the upper geographical scale of a nesting population 
(Bowen \& Karl 2007, Lee 2008). Furthermore, Open Access could provide fundamental information on gene flow among nesting sites, which is assumed to be low in the Mediterranean (Carreras et al. 2006). For instance, we have good knowledge on where nesting grounds are located globally (Mazaris et al. 2014). Within the Mediterranean, most (75\% loggerhead nests) are found in Greece and Turkey (Margaritoulis 2003, Casale \& Margaritoulis 2010), followed by Cyprus and Syria, with many sporadically nested sites being distributed in the central and east basins (Almpanidou et al. 2016). Most green turtle nests $(99 \%)$ are found in Turkey, Cyprus and Syria, with the remainder occurring in Lebanon, Israel and Egypt (Kasparek et al. 2001, Stokes et al. 2016). However, knowledge on the distribution of beaches with low or sporadic nesting remains incomplete, especially for the beaches of the countries of North Africa, which have not been extensively surveyed, particularly Libya.

Open Access provides a unique opportunity to validate observations and predictions from a broad range of sites. Through compiling information on sporadic nesting, this could provide important insights into how the use of sporadic nesting sites changes over time, to detect new sites of importance in need of protection, which could be achieved through Open Data. The number of clutches laid at different sites is dependent not just on climate, but on other factors, such as predation, sand type/structure, etc. (Wood \& Bjorndal 2000, Katselidis et al. 2013). A recent study of all Mediterranean nesting sites showed that the climatic suitability of current stable sites will remain suitable in the future (Almpanidou et al. 2016). However, other factors may lead to the loss of these sites, such as sea level rise (e.g. Katselidis et al. 2014). Furthermore, Almpanidou et al. (2016) showed that sporadically nested sites might be increasingly used, i.e. such sites might not be past sites that are infrequently used, but may reflect the exploratory nature of turtles in locating alternative sites (Schofield et al. 2010a). However, these analyses and interpretations were based on the modelling of information from specific sites.

\section{Foraging, and wintering grounds of immature and adult turtles}

Open Data could allow researchers with different skillsets, including oceanographers and climatologists, to draw on available information (satellite tracking, particle tracking, genetics, stable isotopes) across a representative sample of sites to develop advanced models and provide novel insights into the connectivity of foraging and wintering grounds used by adult and juvenile turtles, along with the associated threats in these areas. For instance, our knowledge about how nesting grounds are connected to foraging and wintering grounds used by adult females, and some males, is good for key breeding sites on Zakynthos and Cyprus, but poor for most other areas of the Mediterranean (Zbinden et al. 2011, Schofield et al. 2013, Luschi \& Casale 2014, Stokes et al. 2016). Furthermore, knowledge of how foraging habitat use differs between adult males and females (Schofield et al. 2013), as well as how these sites overlap with juvenile developmental habitat, remains limited across the various populations in the Mediterranean. Using particle tracking, 2 recent studies suggested that adult loggerheads remain faithful to foraging areas to which they dispersed as hatchlings (Hays et al. 2010, Casale \& Mariani 2014); however, models were subject to limited data availability. Furthermore, mixed oceanic and neritic foraging strategies have been documented for juveniles and adults in the Mediterranean (Casale et al. 2007, 2012, Schofield et al. 2013), with individuals using up to 5 distinct foraging sites (Schofield et al. 2013), and home ranges varying from $<10 \mathrm{~km}^{2}$ up to $1000 \mathrm{~km}^{2}$ in size (Schofield et al. 2010b). The use of multiple sites has been attributed to forage quality/availability, intraspecific competition or changes to climatic conditions, with some turtles shifting to more favourable latitudes, and others possibly wintering (hibernating) (Broderick et al. 2007, Hochscheid et al. 2007).

Open Data presents an important avenue for researchers with different skills to access sufficient information to make informed decisions about which sites/coastal tracts to protect in order to incorporate the greatest size class and genetic diversity. Ultimately, it is essential to determine how developmental, foraging and wintering grounds are distributed throughout the Mediterranean, as well as the numbers of turtles of different size classes and from different populations that frequent these sites, including the seasonality of use and connectivity across sites.

\section{CONCLUSIONS}

This review used the case of sea turtles in the Mediterranean as an example to demonstrate the potential utility of Open Access, not only to link researchers across multiple countries evaluating dif- 
ferent life-history stages of the same population, but also to draw on the wealth of expertise from other disciplines. The lack of Open Access in ecology is not just an issue in the Mediterranean, but is a global issue, which is further exacerbated by wildlife with complex life histories extending from temperate to tropical areas, crossing multiple countries.

Casale (2011) predicts that 44000 turtles might be killed through bycatch alone in the Mediterranean each year; yet, current estimates indicate that there are only around 9000 female green and loggerhead adults females in total (assuming biannual remigration rates), and possibly only around 1000 adult males for the 2 species combined (assuming annual remigration rates). These estimates are highly uncertain and are subject to assumptions that have only been validated for specific sites. Ultimately, effective conservation planning requires reliable data on wildlife population dynamics (e.g. population size, recruitment and mortality rates, reproductive success and longevity) to guide management effectively (Dulvy et al. 2003, Crick 2004). However, it is not possible to obtain such data for many species, especially in the marine environment, limiting our ability to infer and mitigate actual risks through targeted management. Marine turtles represent one such group, with a variety of different monitoring actions being required in different locations. This task is a mammoth jigsaw puzzle with many numbers of pieces that might, ultimately, be impossible to put together.

Open Data provide a means to standardise methods to allow the integrated use of data, and to combine existing published and unpublished information using different tools from different sites over different time periods. Access to such information would allow researchers from different disciplines and with different skill sets to develop robust estimates and predictions, which would improve the protection effort of sea turtles as well as ensuring the delineation of appropriate networks of sites to maximise protection. In particular, the scope of most peer-reviewed journals today states a preference for multi-species and multi-site studies, which ultimately requires multi-group collaborations, with Open Data providing the ideal medium to locate viable national and international collaborators who own data that, otherwise, would not be published. In conclusion, Open Data promotes collaboration at an international scale, drawing together people with similar objectives and different skill sets, whose combined expertise could help determine how best to protect sea turtles and ensure their persistence into the future.

\section{LITERATURE CITED}

Almpanidou V, Costescu J, Schofield G, Türkozan O, Hays GC, Mazaris AD (2016) Using climatic suitability thresholds to identify past, present and future population viability. Ecol Indic 71:551-556

Bjorndal KA (1997) Foraging ecology and nutrition of sea turtles. In: Lutz PL, Musick JA (eds) The biology of sea turtles. CRC Marine Science Series, CRC Press, Boca Raton, FL, p 199-231

Bolten AB (2003) Active swimmers - passive drifters: the oceanic juvenile stage of loggerheads in the Atlantic system. In: Bolten $\mathrm{AB}$, Witherington $\mathrm{BE}$ (eds) Loggerhead sea turtles. Smithsonian Books, Washington, DC, p 63-78

* Bowen BW, Karl SA (2007) Population genetics and phylogeography of sea turtles. Mol Ecol 16:4886-4907

Broderick AC, Godley BJ, Hays GC (2001) Trophic status drives interannual variability in nesting numbers of marine turtles. Proc Biol Sci 268:1481-1487

* Broderick AC, Glen F, Godley BJ, Hays GC (2002) Estimating the number of green and loggerhead turtles nesting annually in the Mediterranean. Oryx 36:227-235

Broderick AC, Glen F, Godley BJ, Hays GC (2003) Variation in reproductive output of marine turtles. J Exp Mar Biol Ecol 288:95-109

*Boderick AC, Coyne MS, Fuller WJ, Glen F, Godley BJ (2007) Fidelity and overwintering of sea turtles. Proc Biol Sci 274:1533-1538

* Cardona L, Revelles M, Carreras C, San Félix M, Gazo M, Aguilar A (2005) Western Mediterranean immature loggerhead turtles: habitat use in spring and summer assessed through satellite tracking and aerial surveys. Mar Biol 147:583-591

* Carreras C, Pont S, Maffucci F, Pascual M and others (2006) Genetic structuring of immature loggerhead sea turtles (Caretta caretta) in the Mediterranean Sea reflects water circulation patterns. Mar Biol 149:1269-1279

* Carroll C, Miquelle DG (2006) Spatial viability analysis of Amur tiger Panthera tigris altaica in the Russian Far East: the role of protected areas and landscape matrix in population persistence. J Appl Ecol 43:1056-1068

Casale P (2011) Sea turtle by-catch in the Mediterranean. Fish Fish 12:299-316

Casale P, Margaritoulis D (eds) (2010) Sea turtles in the Mediterranean: distribution, threats and conservation priorities. IUCN/SSC Marine Turtle Specialist Group. IUCN, Gland. http://iucn-mtsg.org/publications/medreport/

C Casale P, Mariani P (2014) The first 'lost year' of Mediterranean sea turtles: dispersal patterns indicate subregional management units for conservation. Mar Ecol Prog Ser 498:263-274

* Casale P, Freggi D, Basso R, Vallini C, Argano R (2007) A model of area fidelity, nomadism, and distribution patterns of loggerhead sea turtles (Caretta caretta) in the Mediterranean Sea. Mar Biol 152:1039-1049

Casale P, Broderick AC, Freggi D, Mencacci R, Fuller WJ, Godley BJ, Luschi P (2012) Long-term residence of juvenile loggerhead turtles to foraging grounds: a potential conservation hotspot in the Mediterranean. Aquat Conserv 22:144-154

Casale P, Freggi D, Cinà A, Rocco M (2013) Spatio-temporal distribution and migration of adult male loggerhead sea turtles (Caretta caretta) in the Mediterranean Sea: fur- 
ther evidence of the importance of neritic habitats off North Africa. Mar Biol 160:703-718

Casale P, Freggi D, Furii G, Vallini C and others (2014) Annual survival probabilities of juvenile loggerhead sea turtles indicate high anthropogenic impact to Mediterranean populations. Aquat Cons Mar Freshw Ecosyst 25: $690-700$

* Clusa M, Carreras C, Pascual M, Gaughran FJ and others (2014) Fine-scale distribution of juvenile Atlantic and Mediterranean loggerhead turtles (Caretta caretta) in the Mediterranean Sea. Mar Biol 161:509-519

Coll M, Piroddi C, Steenbeek J, Kaschner K and others (2010) The biodiversity of the Mediterranean Sea: estimates, patterns, and threats. PLOS ONE 5:e11842

Costello MJ, Wieczorek J (2014) Best practice for biodiversity data management and publication. Biol Conserv 173: 68-73

Crick HQP (2004) The impact of climate change on birds. Ibis 146:48-56

Demography Working Group (2015) Demography of marine turtles nesting in the Mediterranean Sea: a gap analysis and research priorities. 5th Mediterranean Conference on Marine Turtles, Dalaman, Turkey, 19-23 April 2015. Document T-PVS/Inf (2015)15E presented at the Convention on the Conservation of European Wildlife and Natural Habitats. 35th meeting of the Standing Committee. Strasbourg, 1-4 December 2015

* Dulvy NK, Sadovy Y, Reynolds JD (2003) Extinction vulnerability in marine populations. Fish Fish 4:25-64

* Dutton DL, Dutton PH, Chaloupka M, Boulon RH (2005) Increase of a Caribbean leatherback turtle Dermochelys coriacea nesting population linked to long-term nest protection. Biol Conserv 126:186-194

Encalada SE, Bjorndal KA, Bolten AB, Zurita JC and others (1998) Population structure of loggerhead turtle (Caretta caretta) nesting colonies in the Atlantic and Mediterranean as inferred from mitochondrial DNA control region sequences. Mar Biol 130:567-575

Fuentes MMPB, Limpus CJ, Hamann M (2011) Vulnerability of sea turtle nesting grounds to climate change. Glob Change Biol 17:140-153

Godley BJ, Barbosa C, Bruford M, Broderick AC and others (2010) Unravelling migratory connectivity in marine turtles using multiple methods. J Anim Ecol 47:769-778

*Hamann M, Godfrey MH, Seminoff JA, Arthur K and others (2010) Global research priorities for sea turtles: informing management and conservation in the 21st century. Endang Species Res 11:245-269

Hatase H, Takai N, Matsuzawa Y, Sakamoto W and others (2002) Size-related differences in feeding habitat use of adult female loggerhead turtles Caretta caretta around Japan determined by stable isotope analyses and satellite telemetry. Mar Ecol Prog Ser 233:273-281

Hawkes LA, Broderick AC, Coyne MS, Godfrey MH and others (2006) Phenotypically linked dichotomy in sea turtle foraging requires multiple conservation approaches. Curr Biol 16:990-995

* Hays GC, Broderick AC, Glen F, Godley BJ, Houghton JDR, Metcalfe JD (2002) Water temperature and internesting intervals for loggerhead (Caretta caretta) and green (Chelonia mydas) sea turtles. J Therm Biol 27:429-432

Hays GC, Fossette S, Katselidis KA, Mariani P, Schofield G (2010) Ontogenetic development of migration: Lagrangian drift trajectories suggest a new paradigm for sea turtles. J R Soc Interface 7:1319-1327
Hays GC, Mazaris AD, Schofield G (2014) Different male vs. female breeding periodicity helps mitigate offspring sex ratio skews in sea turtles. Front Mar Sci 1:43

*Hirth HF, Schaffer WM (1974) Survival rate of the green turtle, Chelonia mydas, necessary to maintain stable populations. Copeia 1974:544-546

* Hochscheid S, Bentivegna F, Bradai MN, Hays GC (2007) Overwintering behaviour in sea turtles: dormancy is optional. Mar Ecol Prog Ser 340:287-298

Hooker SK, Cañadas A, Hyrenbach D, Corrigan C, Polovina JJ, Reeves RR (2011) Making protected area networks effective for marine top predators. Endang Species Res 13:203-218

*Hyrenbach KD, Forney KA, Dayton PK (2000) Marine protected areas and ocean basin management. Aquat Conserv 10:437-458

IUCN (2016) The IUCN Red List of Species. www.iucn redlist.org (accessed 15 January 2016)

Kasparek M, Godley BJ, Broderick AC (2001) Nesting of the green turtle, Chelonia mydas, in the Mediterranean: a turtle nesting at Akyatan beach Turkey, 1994-1997. Zool Middle East 24:45-74

Katselidis KA, Schofield G, Stamou G, Dimopoulos P, Pantis J (2012) Females first? Past, present and future variability in offspring sex ratio at a temperate sea turtle breeding area. Anim Conserv 15:508-518

K Katselidis KA, Schofield G, Stamou G, Dimopoulos P, Pantis $J$ (2013) Evidence-based management to regulate the impact of tourism at a key marine turtle rookery at Zakynthos Island, Greece. Oryx 47:584-594

Katselidis KA, Schofield G, Dimopoulos P, Stamou GN, Pantis JD (2014) Employing sea-level rise scenarios to strategically select sea turtle nesting habitat important for long-term management. J Exp Mar Biol Ecol 450: $47-54$

KLaurent L, Casale P, Bradai MN, Godley BJ and others (1998) Molecular resolution of marine turtle stock composition in fishery bycatch: a case study in the Mediterranean. Mol Ecol 7:1529-1542

* Lee PLM (2008) Molecular ecology of marine turtles: new approaches and future directions. J Exp Mar Biol Ecol 356:25-42

Limpus (1993) The green turtle, Chelonia mydas, in Queensland: breeding males in the southern Great Barrier Reef. Wildlife Res 20:513-523

Limpus CJ, Limpus DJ, Arthur KE, Parmeter CJ (2005) Monitoring green turtle population dynamics in Shoalwater Bay 2000-2004. Great Barrier Reef Marine Park Authority, Townsville

Luschi P, Casale P (2014) Movement patterns of marine turtles in the Mediterranean Sea: a review. Ital J Zool 81: 478-495

Margaritoulis D, Argano R, Baran I, Bentivegna F (2003) Loggerhead turtles in the Mediterranean Sea In: Bolten $A B$, Witherington BE (eds) Loggerhead sea turtles Smithsonian Books, Washington, DC, p 175-198

Mazaris AD, Fiksen Ø, Matsinos YG (2005) Using an individual based model for assessment of sea turtle population viability. Popul Ecol 47:179-191

* Mazaris AD, Matsinos YG, Pantis JD (2008) Evaluating the effect of varying clutch frequency in nesting trend estimation of sea turtles. Amphib-Reptil 29:361-369

*Mazaris AD, Kallimanis AS, Tzanopoulos J, Sgardelis SP, Pantis JD (2009a) Sea surface temperature variations in core foraging grounds drive nesting trends and phenol- 
ogy of loggerhead turtles in the Mediterranean Sea. J Exp Mar Biol Ecol 379:23-27

Mazaris AD, Matsions G, Pantis JD (2009b) Evaluating the impacts of coastal squeeze on sea turtle nesting. Ocean Coast Manag 52:139-145

Mazaris AD, Almpanidou V, Wallace B, Schofield G (2014) A global gap analysis of sea turtle protection coverage. Biol Conserv 173:17-23

* Mazaris AD, Vokou D, Almpanidou V, Türkozan O, Sgardelis SP (2015) Low conservatism of the climatic niche of sea turtles and implications for predicting future distributions. Ecosphere 6:1-12

Mazaris AD, Schofield G, Gkazinou C, Almpanidou V, Hays GC (2017) Conservation successes in sea turtles: a global fingerprint. Sci Adv (in press)

Pfaller JB, Bjorndal KA, Chaloupka M, Williams KL, Frick MG, Bolten AB (2013) Accounting for imperfect detection is critical for inferring marine turtle nesting population trends. PLOS ONE 8:e62326

Rees AF, Margaritoulis D, Newman R, Riggall TE, Tsaros P, Zbinden JA, Godley BJ (2013) Ecology of loggerhead marine turtles Caretta caretta in a neritic foraging habitat: movements, sex ratios and growth rates. Mar Biol 160:519-529

Reichman OJ, Jones MB, Schildhauer MP (2011) Challenges and opportunities of open data in ecology. Science 331: 703-705

Schofield G, Lilley MKS, Bishop CM, Brown P and others (2009) Conservation hotspots: implications of intense spatial area use by breeding male and female loggerheads at the Mediterranean's largest rookery. Endang Species Res 10:191-202

Schofield G, Hobson VJ, Lilley MKS, Katselidis KA, Bishop CM, Brown P, Hays GC (2010a) Inter-annual variability in the home range of breeding turtles: implications for current and future conservation management. Biol Conserv 143:722-730

Schofield G, Hobson VJ, Fossette S, Lilley MKS, Katselidis KA, Hays GC (2010b) Fidelity to foraging sites, consistency of migration routes and habitat modulation of home range on sea turtles. Divers Distrib 16:840-853

Schofield G, Dimadi A, Fossette S, Katselidis KA and others (2013) Satellite tracking large numbers of individuals to infer population level dispersal and core areas for the protection of an endangered species. Divers Distrib 19: 834-844

Scott R, March R, Hays GC (2012) Life in the really slow lane: loggerhead sea turtles mature late relative to other reptiles. Funct Ecol 26:227-235

Shaffer SA, Tremblay Y, Weimerskirch H, Scott D and others (2006) Migratory shearwaters integrate oceanic resources across the Pacific Ocean in an endless summer. Proc Natl Acad Sci USA 103:12799-12802

Shillinger GL, Palacios DM, Bailey H, Bograd SJ and others

Editorial responsibility: Konstantinos Stergiou,

Thessaloniki, Greece
(2008) Persistent leatherback turtle migrations present opportunities for conservation. PLOS Biol 6:e171

Shogren JF, Tschirhart J, Anderson T, Whritenour AA and others (1999) Why economics matters for endangered species protection. Conserv Biol 13:1257-1261

Southwood A, Avens L (2010) Physiological, behavioral, and ecological aspects of migration in reptiles. J Comp Physiol B 180:1-23

Stokes KL, Fuller WJ, Godley BJ, Hodgson DJ, Rhodes KA, Snape RTE, Broderick AC (2014) Detecting green shoots of recovery: the importance of long-term individual-based monitoring of marine turtles. Anim Conserv 17:593-602

Stokes KL, Broderick AC, Canbolat AF, Candan O, Fuller WJ, Glen F, Godley BJ (2016) Migratory corridors and foraging hotspots: critical habitats identified for Mediterranean green turtles. Divers Distrib 21:665-674

* Turner W, Rondinini C, Pettorelli N, Mora B and others (2015) Free and open-access satellite data are key to biodiversity conservation. Biol Conserv 182:173-176

*Wallace BP, DiMatteo AD, Hurley BJ, Finkbeiner EM and others (2010) Regional management units for marine turtles: a novel framework for prioritizing conservation and research across multiple scales. PLOS ONE 5:e15465

Wallace BP, DiMatteo AD, Bolten AB, Chaloupka MY and others (2011) Global conservation priorities for marine turtles. PLOS ONE 6:e24510

*Whiting AU, Chaloupka M, Limpus CJ (2013) Comparing sampling effort and errors in abundance estimates between short and protracted nesting seasons for sea turtles. J Exp Mar Biol Ecol 449:165-170

*Whiting AU, Chaloupka M, Pilcher N, Basintal P, Limpus CJ (2014) Comparison and review of models describing sea turtle nesting abundance. Mar Ecol Prog Ser 508:233-246

Wilson B, Reid RJ, Grellier K, Thompson PM, Hammond PS (2004) Considering the temporal when managing the spatial: a population range expansion impacts protected areas-based management for bottlenose dolphins. Anim Conserv 7:331-338

*Womble JN, Gende SM (2013) Post breeding season migrations of a top predator, the harbour seal (Phoca vitulina richardii), from a marine protected area in Alaska. PLOS ONE 8:e55386

*Wood DW, Bjorndal KA (2000) Relation of temperature, moisture, salinity, and slope to nest site selection in loggerhead sea turtles. Copeia 2000:119-128

* Zbinden JA, Largiadèr CR, Leippert F, Margaritoulis D, Arlettaz R (2007) High frequency of multiple paternity in the largest rookery of Mediterranean loggerhead sea turtles. Mol Ecol 16:3703-3711

K Zbinden JA, Bearhop S, Bradshaw P, Gill B, Margaritoulis D, Newton J, Godley BJ (2011) Migratory dichotomy and associated phenotypic variation in marine turtles revealed by satellite tracking and stable isotope analysis. Mar Ecol Prog Ser 421:291-302

Submitted: December 16, 2016; Accepted: March 2, 2017

Proofs received from author(s): April 19, 2017 